\title{
Pain management in endodontics
}

\author{
Monisha P. Khatri ${ }^{1, *}$, Sheetal Ghivari², Madhu Pujar ${ }^{3}$, Hemant Vagarali ${ }^{4}$, Veerendra Uppin ${ }^{5}$ \\ ${ }^{1}$ PG Student, ${ }^{2}$ Reader, ${ }^{3-5}$ Professor, Dept. of Conservative Dentistry \& Endodontics, Maratha Mandal Dental College, Belgaum, \\ Karnataka, India
}

*Corresponding Author:

Email: drkhatrimonisha@gmail.com

\begin{abstract}
Pain is a stimuli that causes the greatest fear in any patient who requires an endodontic treatment. This fear if tackled efficiently not only improves the success of the treatment but also creates a strong dentist patient relationship. Pain management can be done effectively by using various pharmacological regimes such as anxiolytics, local anaesthetics, NSAIDs and opioids. These drugs have proven to reduce pain and help the patient overcome the fear associated with endodontic treatment. This article briefly discusses the drugs, its dosage and properties that are commonly used to manage endodontic pain.
\end{abstract}

Keywords: Anxiolytics, Local anaesthesia, NSAIDs, Opioids, Pain pathway.

\section{Introduction}

The fear of pain is the greatest fear that makes most of the patients hesitant to approach a dentist for the treatment. Therefore managing pain is an art that every dentist should persist to gain the confidence of patients and complete the treatment in the most satisfactory manner.

The management of pain represents both a challenge and an opportunity for the endodontist. It is a challenge due to pharmacological, behavioural and practice management issues.

Endodontic pain management encompasses all aspects of treatment: preoperative pain control includes accurate diagnosis and anxiety reduction; intraoperative pain control revolves around effective local anaesthetic and operative techniques; and postoperative pain management can involve a variety of pharmacologic agents. Therefore this review throws a light on the common analgesics used in endodontic practise which includes anti anxiety drugs, local anaesthetics and non steroidal anti inflammatory drugs (NSAIDs).

\section{Pain and its pathways}

Inflammatory mediators such as bradykinin, serotonin, prostaglandins, cytokines and $\mathrm{H}+$ are released from damaged tissue which stimulate the nociceptors that carry the noxious stimulti to the central nervous system. This stimuli is carried to the brain by the free nerve endings of primary afferent $\mathrm{A} \delta$ and $\mathrm{C}$ fibres.

A $\delta$ fibres are lightly myelinated and smaller diameter fibres that respond to mechanical and thermal stimuli. They are responsible for the rapid, sharp pain and initial reflex response to acute pain. $\mathrm{C}$ fibres are unmyelinated, smallest diameter fibres which demonstrate the slowest conduction. They respond to chemical, mechanical and thermal stimuli and their activation leads to slow burning pain. These fibres carry the nocioceptor signals to higher centres in the brain by the the spinothalamic tract and the spinoreticular tract. While the spinothalamic tract is associated with pain localisation, the emotional aspect of pain is due to the spinoreticular tract. ${ }^{1-3}$

\section{Anxiolytics}

Anxiolytics or psycholeptics are drugs that cause soothing effects and decrease the anxiety level. In enodontics it can be used in cases of trauma, swelling like abscess or cellulitis or in patients in grave fear and apprehension. The commonly used anxiolytics are benzodiazepine (BZD) such as Diazepam, Lorazepam and Triazolam.

\section{Benzodiazepine}

BZD in endodontics have proved to be advantageous due to their inherent properties such as skeletal muscle relaxation, patients consciousness is not lost, no effect on respiration, cardiovascular functions or any other body system, less sleep distortion and low abuse liability. ${ }^{4}$

\section{Mechanism of action}

BZD has the affinity for the $\mathrm{GABA}_{\mathrm{A}}$ Subunit of Gamma amino butyric acid (GABA), which is an inhibitory neurotransmitter. These BZD bind at the $\beta$ subunit of GABA and cause increase in the frequency of chloride channel opening and influx of Chloride ions. This influx further result in a hyperpolarized state and decreases the firing rate of the neurons thus causing the anxiolytic effect. ${ }^{4}$

\section{Commonly used BZD}

The BZD that is most commonly preferred in dental practise is triazolam as it has a fast onset of action, short duration of effect, short elimination halflife and early recovery. ${ }^{5}$

Diazepam is amongst the oldest used anti anxiety drugs .Though its efficacy as an anxiolytic and sedative 
is commendable it causes sedation hours later after the initial effect which restricts its use in endodontics. ${ }^{5}$ It is rapidly absorbed and has a fast onset of action. ${ }^{4}$

Lorazepam is a commonly used sedative. Due to its poor lipid solubility its onset of action ranges within an uncertain limit of 1 to 6 hours. ${ }^{5}$ Since it has a longer duration of action it can be given in cases of endodontic surgery or where multiple root canal therapies have to be performed.

Though BZD are relatively safe drugs side effects may include dizziness, vertigo, ataxia, disorientation, amnesia, impairment of psychomotor skills therefore patient should not drive after its use. All the BZD are excreted in urine, crosses the placenta and are secreted in milk therefore are contraindicated in pregnancy and lactating mothers. ${ }^{4}$

\section{Dosage $^{4}$}

Diazepam- 5-10mg, 6-12 hrs

Lorazepam: 0.5-1.0 mg, 12-24 hrs

Triazolam: 0.125-0.25 mg, $24 \mathrm{hrs}$

\section{Local Anaesthesia (LA)}

LA causes loss of sensation in a circumscribed area of the body by depression of excitation in nerve endings or an inhibition of the conduction process in the peripheral nerves. ${ }^{6}$ They are classified according to their duration of action as intermediate or long duration, based on type of intermediate chain as amide or ester, based on surface anaesthesia as soluble and insoluble. ${ }^{4}$ The commonly used LA agents are amides such as lignocaine, benzocaine, prilocaine and articaine.

\section{Mechanism of action}

According to the specific receptor theory LA binds to specific receptors present in the sodium channel and blocks the influx of sodium ions in to their channels. This prevents the increase in permeability of the nerve membrane to sodium that is responsible for nerve conduction. Displacement of calcium from the ion channels is said to be the primary factor responsible for competitively binding of LA at the channel and decreasing the sodium conductance. ${ }^{7,8}$

\section{Commonly used LA agents Lignocaine}

Lignocaine is the most versatile LA that serves both for surface application as well as injection and is available in a variety of forms. Its anaesthetic effect is more intense, long lasting and causes its action in 3 minutes. Vasoconstrictors are added to prolong its duration of action and therefore 2 percent with 1:100,000 epinephrine vasoconstrictor, and

2 percent with 1:50,000 epinephrine are commonly used which have a have a pulpal duration of 1-1.5 hours and a soft-tissue range of three to five hours ${ }^{9,10}$.

\section{Benzocaine}

Topical anaesthetics may be indicated to minimize the sensation of needle insertion or for very brief relief from painful mucosal lesions. $20 \%$ benzocaine is most commonly used topical anaesthesia. They are available in gel as well as solution form. They produce longlasting anaesthesia without systemic toxicity. ${ }^{9,10}$

\section{Prilocaine}

Prilocaine is an alternative to patients in whom vasoconstrictor is contraindicated as it has mild vasodilatory effect compared to other amides. It is less toxic, less potent than lidocaine and its duration of action is slightly longer. It is available as $4 \%$ prilocaine with 1:200,000 epinephrine and 4\% prilocaine (plain). Contraindicated in patients with methemoglobinemia and true amide type allergy. ${ }^{9,} 10$

\section{Articaine}

Following lignocaine, $4 \%$ solution of articaine with $1: 100,000$ epinephrine is the most common anaesthetic agent used. It has a faster duration of action of 1.4 to 3.6 minutes, longer profound level of anesthesia and increased tissue diffusability. It provides pulpal anaesthesia for 1 hour with soft-tissue anaesthesia for 24 hours. They should be used with caution in inferior alveolar and lingual nerve block injections as they show an increased risk of nerve paresthesia. ${ }^{9,10}$

All the amides are degraded in liver microsomes and excreted by the kidneys. Hypersensitivity reactions like rashes, angioedema, dermatitis, asthma may occur. Vasoconstrictor containing LA should be avoided for patients with ischemic heart disease, cardiac arrhythmia, thyrotoxicosis, uncontrolled hypertension, and those receiving $\beta$ blockers or tricyclic antidepressants. $^{4}$

\section{Recommended maximum dose of LA with vasoconstriction ${ }^{8,10}$ :}

\begin{tabular}{|l|l|c|}
\hline \multicolumn{1}{|c|}{ Drug } & \multicolumn{1}{c|}{ Maximum dose } & Maximum no. of catridges \\
\hline Lignocaine & $7 \mathrm{mg} / \mathrm{kg}$ (up to $500 \mathrm{mg}$ ) & 13 \\
\hline Prilocaine & $8 \mathrm{mg} / \mathrm{kg}$ (up to $500 \mathrm{mg})$ & 8 \\
\hline Articaine & $\begin{array}{l}7 \mathrm{mg} / \mathrm{kg} \text { (up to } 500 \mathrm{mg}) \\
5 \mathrm{mg} / \mathrm{kg} \text { in children }\end{array}$ & 7 \\
\hline
\end{tabular}




\section{Non steroidal anti inflammatory drugs}

The major analgesic drug class for treating endodontic pain are the nonsteroidal anti-inflammatory analgesics and acetaminophen. They produce their analgesic and anti-inflammatory effect by inhibiting the enzyme cyclo oxygenase and are mainly useful in the initial pain management that has an inflammatory component.

\section{Mechanism of action}

Prostaglandins and thromboxane $\mathrm{A}_{2}\left(\mathrm{TXA}_{2}\right)$ collectively termed as prostanoids are formed when arachidonic acid is metabolized by cyclooxygenase enzyme. They exist in different isoenzyme forms such as COX-1 and COX-2.These 2 cyclooxygenase enzymes are the target site of NSAIDs. Depending on their site of action they may be classified as non selective cox inhibitors such as ibuprofen, diclofenac and ketorolac, selective cox-2 inhibitors such as celecoxib and analgesic- antipyretics with poor antiinflammatory action like acetaminophen. ${ }^{4}$

\section{Ibuprofen}

First member of class of Propionic acid derivative and is commonly used NSAID in endodontics. They are well absorbed orally and inhibit platelet function therefore should not be taken with anticoagulants. Contraindicated in pregnancy and peptic ulcer patients. ${ }^{11}$

Dosage $^{12}$ : 200-400 mg, 4-6hourly

\section{Diclofenac}

Diclofenac exists in two forms known as Diclofenac Sodium and Diclofenac Potassium. Diclofenac potassium has an immediate release as they are rapidly soluble in water while Diclofenac sodium has delayed release. Hence for acute and severe pain, it is better to take Diclofenac potassium than Diclofenac sodium. ${ }^{13}$

Dosage $^{12}: 50 \mathrm{mg}, 8$ hourly

\section{Ketorolac}

Its a novel pyrrolo pyyrole derivative with potent analgesic and modest anti-inflammatory activity. It has an efficacy equivalent to that of morphine without the side effects usually associated with opioids. It is advised to use Ketorolac in chronic pain conditions and its use for more than 5 days should be avoided as it may cause gastrointestinal bleeding, peptic ulceration, renal failure, or hematological dysfunction due to inhibited platelet aggregation with thromboxane inhibition. ${ }^{14}$ Dosgae $^{12}: 10 \mathrm{mg}$ 4-6 hourly for short term management of moderate pain.

\section{Piroxicam}

Piroxicam is a reversible inhibitor of COX which is long-acting with good anti-inflammatory and analgesicantipyretic action. It also decreases the production of
IgM rheumatoid factor and leucocyte chemotaxis and therefore can inhibit inflammation in diverse ways. ${ }^{11}$ Dosage $^{12}: 40 \mathrm{mg}$ once a day followed by $20 \mathrm{mg}$ OD

\section{Celecoxib}

The COX-2 selectivity of celecoxib is modest with equal analgesic and anti inflammatory efficacy as the conventional NSAIDs. Its added advantage is it has low ulcerogenic potential which gives minimal GIT irritation and no increase in bleeding time. ${ }^{15}$ It is slowly absorbed with elimination half life of 11 hours. ${ }^{16}$

Dosage ${ }^{4}: 100-200 \mathrm{mg}$ bid

\section{Acetaminophen}

Also known as paracetamol (PCT) is the safest analgesic that blocks the prostaglandin pathway within the central nervous system. It has a good analgesic and antipyretic action but no anti inflammatory effect as it does not act directly on the peripheral tissue. ${ }^{17}$ It has good oral absorption, effect lasts for 3-5 hrs and is excreted rapidly in urine. PCT does not cause any significant gastric irritation, mucosal erosion, bleeding and also does not affect platelet function or clotting factors. ${ }^{4}$ The major adverse effect of acetaminophen is hepatotoxicity therefore in patients with chronic alcoholism its maximum dose should be limited to $2 \mathrm{~g}$ per day compared to $4 \mathrm{~g}$ per day. ${ }^{17}$

Dosage $^{12}: 325-650 \mathrm{mg}$ for every 4-6 hourly.

\section{Adverse effects and contraindications of NSAIDs}

They may cause gastrointestinal disturbances such as gastric irritation, erosions, peptic ulcerations, renal impairment, headache, mental confusion, bleeding, asthma exacerbation and anaphylactic reactions. Therefore they are contraindicated in patients with gastrointestinal diseases, bleeding disorders, asthma, hypersensitivity, third trimester of pregnancy and chronic renal disease as they are majorly excreted via the kidneys and rest by bile. It should not be given to patients consuming drugs like diuretics or betablockers, ACE inhibitors, anticoagulants like warfarrin, methotrexate, digoxin and alcohol. ${ }^{7,18}$

\section{Opioids}

Opioids are indicated in cases of moderate to severe pain if PCT and NSAIDs are ineffective. Pertaining to the side effects associated with opioids it is advised to use it in combination regime with PCT or NSAIDs with doses of the latter two to being higher. Commonly used opioids are codeine, oxycodone, hydrocodone and tramadol.

\section{Mechanism of Action}

Opioids are $\mathrm{G}$ protein coupled receptors that act on $\mu, \mathrm{K}$ and $\delta$ receptors present on the neurons in the CNS and in peripheral tissues. They cause their analgesic effect by inhibiting the neurotransmitter release either by inhibiting the calcium entry, by enhancing outward 
movement of potassium ions or by inhibiting adenylate cyclase. $^{4}$

\section{Commonly used opioids \\ Codeine}

Codeine is methyl-morphine that partly gets converted to morphine in the body that is responsible for its analgesic effect. Codeine has good activity orally and its effect lasts for 4-6 hours. Abuse liability is low and causes constipation when used in analgesic doses. Used with aspirin or PCT in mild to moderate pain. ${ }^{19}$ Dosage $^{20}$ : 180-200mg every 4-6 hourly.

\section{Oxycodone and hydrocodone}

They are semi synthetic opioids indicated for moderate to severe pain. Onset of action is 10- 30 minutes with instant action of 3-6 hours that starts reducing pain in 10-15 minutes on empty stomach. Hydrocodone is available orally and has onset of action of 10 to 20 minutes with effect lasting for 4-8hrs. ${ }^{4}$ Dosage of oxycodone and hydrocodone ${ }^{20}: 20-30 \mathrm{mg}, 4-$ 8 hourly.

\section{Tramadol}

Tramadol is a synthetic analogue of codeine which has an action on the $\mu$-opioid receptor that helps to reduce pain. It's effective for moderately severe pain, especially if patient is already on NSAIDs for acute pain management. Its effect lasts for 4-6 hrs, is available in combination with PCT and decreases the risk of constipation. ${ }^{21}$

Dosage $^{21}$ : 50-100mg, 4-6 hourly

\section{Adverse effects and contraindications of opioids}

Opioids cause sedation, respiratory depression, dependence, nausea, miosis, and constipation ${ }^{17}$. They are contraindicated in patients with severe chronic respiratory disease, severe inflammatory bowel disease and concurrent use of alcohol. ${ }^{7}$

\section{Conclusion}

Careful assessment of the type and intensity of pain helps to select the pharmacological regime required that will aid in the success of an endodontic treatment. Judicious and intelligent use of anti anxiety drugs to relieve stress, local anaesthesia to give a pain free endodontic experience and NSAIDs to prevent the after effects increases the standard of dental treatment. Combination therapy of opioids with analgesics should be ascertained in cases of moderate to severe pain when NSAIDs alone have proved to be unhelpful.

Funding: No funding sources.

Conflict of interest: None declared.

\section{References}

1. LaMotte RH, Lundberg LE, Torebjörk HE. Pain, hyperalgesia and activity in nociceptive $\mathrm{C}$ units in humans after intradermal injection of capsaicin. J Physiol 1992;448(1):749-64.

2. Reddi D, Curran N, Stephens R. An introduction to pain pathways and mechanisms. Br J Hospital Med (London, England: 2005). 2013;74:C188

3. Serpell M. Anatomy, physiology and pharmacology of pain. Surg (oxford). 2006;24(10):350-3.

4. Tripathi KD. Essentials of medical pharmacology. JP Medical Ltd; 2013

5. Haas DA. Oral sedation in dental practice. Royal College of Dental Surgeons of Ontario 2015.

6. Bahl R. Local anesthesia in dentistry. Anesthesia progress 2004;51(4):138.

7. Haas DA. An update on local anesthetics in dentistry. $J$ Can Dent Asso 2002;68(9):546-52.

8. Malamed SF. Handbook of local anesthesia-e-book. Elsevier Health Sciences 2014

9. Budenz AW. Local anesthetics in dentistry: then and now. J California Dent Asso 2003;31(5):388-96.

10. Webb LJ. Dental anesthesia: Overview of injectable agents useful for nonsurgical periodontal therapy. RDH Magazine. 2016;36(1).

11. Katzung BG, Masters SB, Trevor AJ. Basic and Clinical Pharmacology (LANGE Basic Science). McGraw-Hill Education; 2012.

12. Nagi R, Devi BY, Rakesh N, Reddy SS, Patil DJ. Clinical implications of prescribing nonsteroidal antiinflammatory drugs in oral health care-a review. Oral Surg Oral Med Oral Pathol Oral Radiol 2015;119(3):264-71.

13. Altman R, Bosch B, Brune K, Patrignani P, Young C. Advances in NSAID development: evolution of diclofenac products using pharmaceutical technology. Drugs 2015;75(8):859-77.

14. Vadivelu N, Gowda AM, Urman RD, Jolly S, Kodumudi V, Maria M, Taylor Jr R, Pergolizzi Jr JV. Ketorolac tromethamine-routes and clinical implications. Pain Practice 2015;15(2):175-93.

15. Chou R, Helfand M, Peterson K, Dana T, Roberts C. Drug class review on cyclo-oxygenase (COX)-2 inhibitors and non-steroidal anti-inflammatory drugs (NSAIDs). Final report update. 2006 Nov;3.

16. Goodman LS. Goodman and Gilman's the pharmacological basis of therapeutics. New York: McGraw-Hill; 1996

17. Becker DE, Phero JC. Drug therapy in dental practice: nonopioid and opioid analgesics. Anesthesia progress. 2005;52(4):140-9.

18. Haas DA. An update on analgesics for the management of acute postoperative dental pain. $J$ Can Dent Asso 2002;68(8):476-84.

19. Cherny NI. Opioid analgesics. Drugs 1996;51(5):713-37.

20. Becker DE. Pain management: Part 1: Managing acute and postoperative dental pain. Anesthesia progress 2010;57(2):67-79.

21. Moore PA. Pain management in dental practice: tramadol vs. codeine combinations. J Am Dent Asso 1999;130(7):1075-9.

How to cite the article: Pain management in endodontics. Khatri M., Ghivari S, Pujar M., Vagarali H., Uppin V. IP Indian J Conserv Endod 2018;3(3):6568. 
